\title{
Avaliação de concreto asfáltico usinado a quente com incorporação de material fresado
}

\author{
Performance evaluation of hot asphalt \\ concrete with incorporation of RAP
}

Cristiane Bolina da Cunha ${ }^{1}$, Jaelson Budny ${ }^{1}$, Rodrigo André Klamt ${ }^{2}$

\author{
${ }^{1}$ Universidade Federal do Pampa, Curso de Engenharia Civil, Avenida Tiarajú, 810, Alegrete, RS, Brasil. \\ e-mail: crisbcunha13@gmail.com, jaelsonbudny@unipampa.edu.br \\ ${ }^{2}$ Universidade Regional Integrada do Alto Uruguai e das Missões, Departamento de Engenharias e Ciência da Computa- \\ ção, Rua Assis Brasil, 709, Frederico Westphalen, RS, Brasil. \\ e-mail: rodrigoklamt@outlook.com,robertacentofante@yahoo.com.br, \\ ${ }^{3}$ Universidade Federal de Santa Maria, Curso de Engenharia Civil, Centro de Tecnologia Sala 134, Av. Roraima, 1000, \\ Cidade Universitária, Camobi, Santa Maria, RS, Brasil. \\ e-mail: magnos.baroni@gmail.com
}

\section{RESUMO}

A escassez dos recursos naturais e a demanda por alternativas de reutilização de materiais tornou a reciclagem uma palavra de ordem no atual cenário da construção rodoviária mundial. A fresagem de pavimentos produz um material de alto valor econômico e com ótimas propriedades físicas e mecânicas que podem ser introduzidas na composição de novas misturas asfálticas. O presente trabalho avaliou o comportamento mecânico de misturas usinadas a quente com adição de diferentes teores de ligante novo, de 2,5\% a 4,5\%. O material de estudo é proveniente da Rodovia Brasileira 290 (BR-290), do trecho situado entre os municípios de Rosário do Sul e São Gabriel, no estado do Rio Grande do Sul (RS). Para caracterização do material fresado foram realizados os ensaios de granulometria, extração de betume, estabilidade e fluência Marshall e resistência à tração por compressão diametral com corpos de prova cilíndricos moldados conforme as misturas propostas. De acordo com os resultados, obtiveram-se valores de estabilidade, fluência e resistência à tração por compressão diametral satisfatórios para a aplicação de material fresado (50\% e $100 \%$ de adição) em misturas asfálticas para camadas de rolamento. Portanto, a reutilização desse material, nas proporções avaliadas, proveniente do próprio pavimento, além de atender as especificações técnicas, também surge como solução para evitar deposição inadequada do mesmo, reduzindo o passivo ambiental.

Palavras-chave: fresado, reciclagem, dosagem, pavimento

\section{ABSTRACT}

The scarcity of natural resources and the demand for alternative reuse of materials has made recycling a slogan in the current scenario of global road construction. A floor milling (Recycled Asphalt Pavement - RAP) yields a material with high economic value and excellent physical and mechanical properties that may be introduced in the composition of new asphalt mixtures, from $2.5 \%$ to $4.5 \%$. This study evaluated the mechanical mixtures machined hot with addition of different amounts of new binder behavior. The study material comes from the Brazilian Highway 290 (BR-290), passage located between the municipalities of Rosario do Sul and São Gabriel, in the state of Rio Grande do Sul (RS). For characterization of the milled material was performed assays grading, bitumen extraction, Marshall stability and creep and tensile strength by diametralcompression proof bodies of cylindrical specimens molded in accordance with the proposals mixtures. According to the results, we obtained values of stability, creep and tensile strength by diametral compression, suitable for the application of milled material (50\% and 100\% addition) in asphalt mixtures for layers bearing. Therefore, the reuse of this material, in the proportions evaluated, from the pavement itself, in addition to meeting the technical specifications, also appears as a solution for the avoid inadequate deposition of the 
same, reducing environmental passive.

Keywords: RAP, recycling, dosing, paving.

\section{INTRODUÇÃO}

Na década de 1970, a construção rodoviária brasileira passou por mudanças no seu cenário de desenvolvimento. Tal fato ocorreu, principalmente, por conta do início das cobranças por parte dos órgãos ambientais, forçando os construtores adequarem o processo de construção rodoviária às normas vigentes na década. Assim, visando também a economia, houve um estímulo na implantação de métodos tecnológicos envolvendo a reciclagem de pavimentos 0 .

Nos anos que se seguiram, a técnica de reciclagem para reabilitação de pavimentos, considerando a reutilização do resíduo oriundo da fresagem na composição da nova camada asfáltica, obteve reconhecimento notório devido a uma série de fatores, dentre estes, o avanço das pesquisas na área possibilitando o conhecimento das características mecânicas dos materiais envolvidos e a conscientização da importância da reciclagem como meio de preservação ambiental. Tal mudança deve-se, principalmente, ao reconhecimento do esgotamento das fontes de recursos naturais, explorados de maneira descontrolada, e da necessidade de se reduzirem os custos de revitalização das vias, onde a reciclagem é designada como uma alternativa para a reabilitação de pavimentos, à medida que é utilizada a reutilização dos materiais constituintes do próprio pavimento para fins de construção e conservação, prolongando o período de exploração e fornecimento nas jazidas e pedreiras [2-5].

Rotineiramente, prefeituras e entidades gestoras precisam recuperar pavimentos envelhecidos, os quais se utilizam da técnica de recapeamento. No entanto, o problema decorrente desta atividade consiste nas diferenças de elevação deixadas, provocando desconforto ao usuário 0. Assim, para diminuir os problemas ocasionados pelos recapeamentos sucessivos de vias, é empregada a técnica de fresagem asfáltica do pavimento, com isso, é possível a remoção da camada superficial desgastada, bem como a colocação de uma nova camada devidamente nivelada com o acostamento ou meio-fio existente. Na composição dessa mistura triturada encontra-se brita, areia, filler e CAP (Cimento Asfáltico de Petróleo) 0.

O material fresado, por muito tempo, fora considerado rejeito de construção e destinado a aterros de depósito ou bota-foras previamente determinados pela fiscalização. Atualmente, a fiscalização sobre a destinação do material proveniente da fresagem dos pavimentos, assim como de outras atividades construtivas, é estabelecida pela Resolução ${ }^{\circ} 307$ de 5 de julho de 2002, do Conselho Nacional do Meio Ambiente (CONAMA), que estabelece leis e diretrizes de gestão de resíduos, exigindo que todo órgão gerador de resíduos deverá ter um programa de gestão deste material, de forma a minimizar os impactos ambientais 00 .

Tendo em vista o crescimento sustentável, e em conformidade com a resolução $\mathrm{n}^{\circ} 307$, órgãos de gestão vêm procurando soluções ecológicas como uma das alternativas economicamente viáveis e politicamente corretas. Um exemplo disto é a reciclagem do pavimento existente, onde o grande benefício é a possibilidade de reutilização de quase todo o material constituinte da via restaurada, propiciando menor consumo de energia e de recursos naturais não renováveis 0 . Então, em razão da importância desta atividade, devido ao esgotamento dos recursos naturais e locais para depósito de resíduos, a reciclagem de revestimento asfáltico está se tornando um procedimento rotineiro.

Usualmente, materiais reciclados provenientes da fresagem de camadas asfálticas são reutilizados em camadas de base de pavimentos [9]. Trata-se de uma ótima solução para destinação destes resíduos e preservação ambiental, porém este tipo de solução subestima o valor do material presente na camada fresada, que tem por principal característica a presença de ligante asfáltico, um dos componentes de maior valor econômico na composição de um pavimento.

Várias são as pesquisas realizadas através da aplicação da técnica da reutilização dos materiais reciclados em camadas de pavimento [2; 9-12]. A aplicação de fresado em camadas novas consiste na aplicação deste resíduo a fim de se obter uma redução em seu valor econômico, bem como no consumo de materiais novos, além de aumentar a capacidade de carga e proteger o meio ambiente. No entanto, a principal preocupação com o aumento das porcentagens admissíveis de agregado reciclado em mistura a quente é a presença de materiais envelhecidos, os quais podem fragilizar a mistura e diminuir sua resistência, principalmente à fadiga $[9 ; 13,14]$.

Visando fornecer dados para futuras pesquisas e, ainda, abordar a importância do uso de tecnologias sustentáveis, este trabalho aborda uma análise do desempenho de misturas asfálticas com adição de material fresado para camadas de revestimento, na busca de avaliar as propriedades mecânicas da composição, para aplicação em processos de reciclagem na região da fronteira oeste do Rio Grande do Sul, utilizando amostras 
coletadas na região.

Portanto, o objetivo geral deste estudo é avaliar o comportamento de uma mistura asfáltica, para aplicação em camadas de revestimento usinadas a quente, utilizando material fresado proveniente da Rodovia Brasileira 290 (BR-290), no trecho entre os municípios Rosário do Sul/São Gabriel, ambos no estado do Rio Grande do Sul (RS).

\section{MATERIAIS E MÉTODOS}

\subsection{Composições granulométricas das misturas}

Para fins comparativos, nesta pesquisa, foram realizadas duas misturas compostas de material fresado e agregado novo, no intuito de verificar como seria o comportamento da mistura com $100 \%$ de material fresado foi realizada a mistura referência (M100) e, posteriormente, uma segunda mistura com incorporação de $50 \%$ de agregados virgens (M50).

O material fresado (agregado reciclado) foi obtido através da técnica de fresagem a frio da obra de conservação e restauração do revestimento asfáltico, da BR-290, no trecho Rosário do Sul/São Gabriel - RS. Tal material passou por uma análise granulométrica, objetivando identificar a faixa de enquadramento da amostra, de acordo com a classificação do DNIT (2006) [15]

Os dados obtidos nas amostras serviram para o tamanho das partículas do material fresado ainda envolto com o ligante existente na mistura. Posteriormente, o ligante presente nas amostras de material fresado foi extraído, conforme as especificações e procedimentos para execução do ensaio, indicados pela norma DNER-ME 053 (1994) 0.

Após a extração do ligante, as três amostras foram secas em estufa e passaram pelo processo de análise granulométrica, seguindo as mesmas especificações do ensaio adotado para a granulometria do material com ligante. Essa análise foi realizada para verificar a composição do esqueleto pétreo presente na mistura de material fresado. A curva granulométrica do material fresado, antes e após a extração do ligante, está representada na Figura 1.

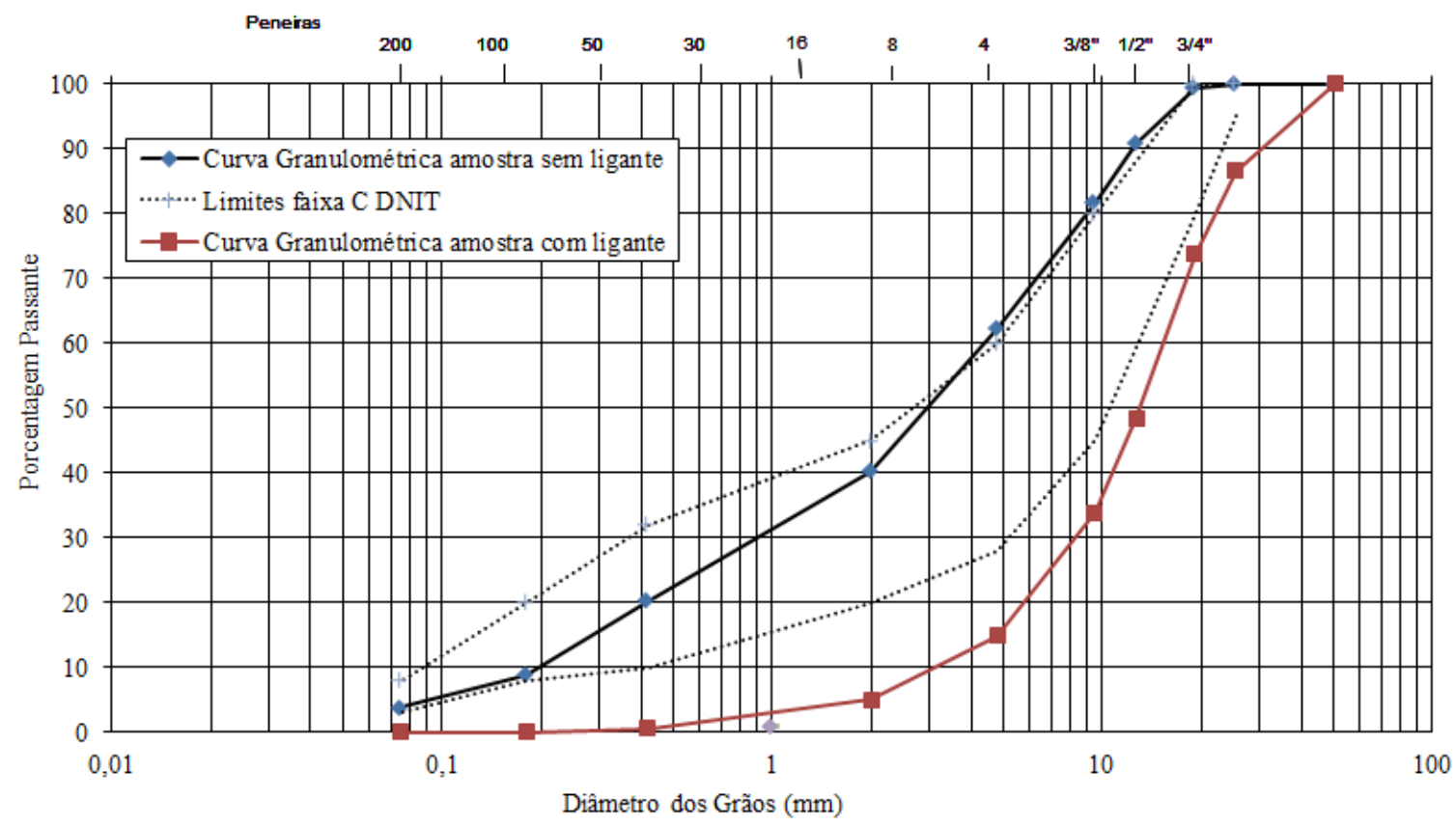

Figura 1: Curvas granulométricas do material fresado antes e após extração de ligante

Para composição da M50, foram utilizados agregados minerais virgens de diferentes graduações. O material foi enquadrado dentro da distribuição granulométrica da faixa "C" do DNIT (2006) [17], visto que a caracterização granulométrica do material fresado mais se aproximou desta faixa. Dessa forma, o ensaio regulamentado pela norma DNER-ME 083 (1998) [18] foi executado para as graduações de brita 0, brita 1 e 
pó de pedra, sendo a curva granulométrica resultante da composição apresentada na Figura 2. Os valores percentuais para cada uma das faixas granulométricas foram ajustados, em unidade de massa, de acordo com os diferentes teores adicionados às misturas.

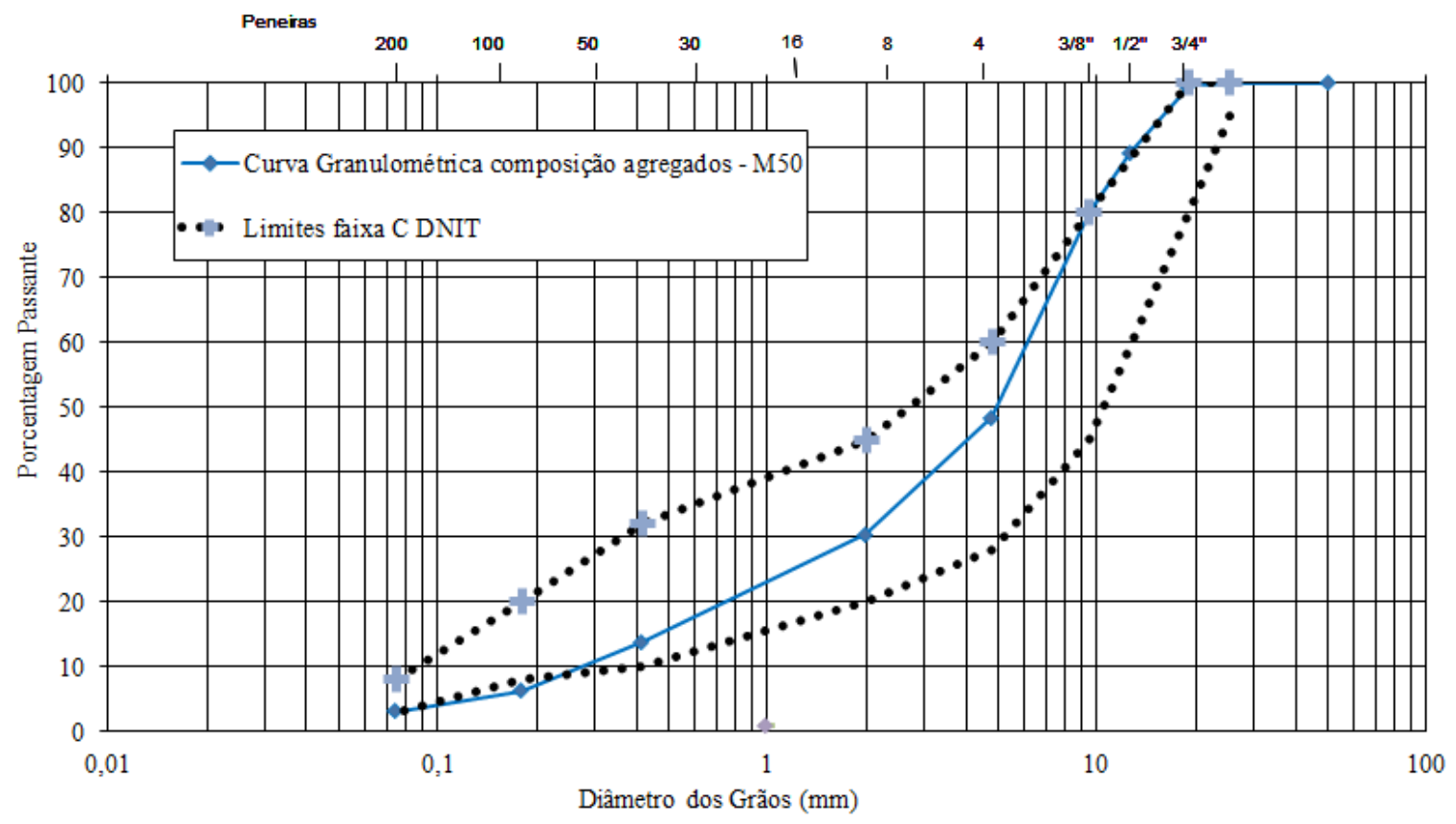

Figura 2: Curva granulométrica da composição dos agregados da M50

\subsection{Ligante asfáltico}

O ligante asfáltico utilizado foi o CAP 50/70 da Petrobrás. Para fins deste trabalho, não foi necessário determinar todas as propriedades de caracterização deste material, uma vez que não representa o foco principal da pesquisa. Apesar disso, é indispensável conhecer as características de trabalhabilidade com a qual se pode aplicar o ligante em misturas. Foi executado o ensaio de viscosidade, de forma a determinar a temperatura com a qual as diferentes misturas podem ser executadas.

A viscosidade do ligante foi determinada utilizando o viscosímetro rotacional, conhecido como viscosímetro de Brookfield. O ensaio, conforme NBR 15184 (2004) [19], determinou as temperaturas para mistura e compactação do CAP. A Figura 3 apresenta a faixa de mistura, compactação e a curva de viscosidade.

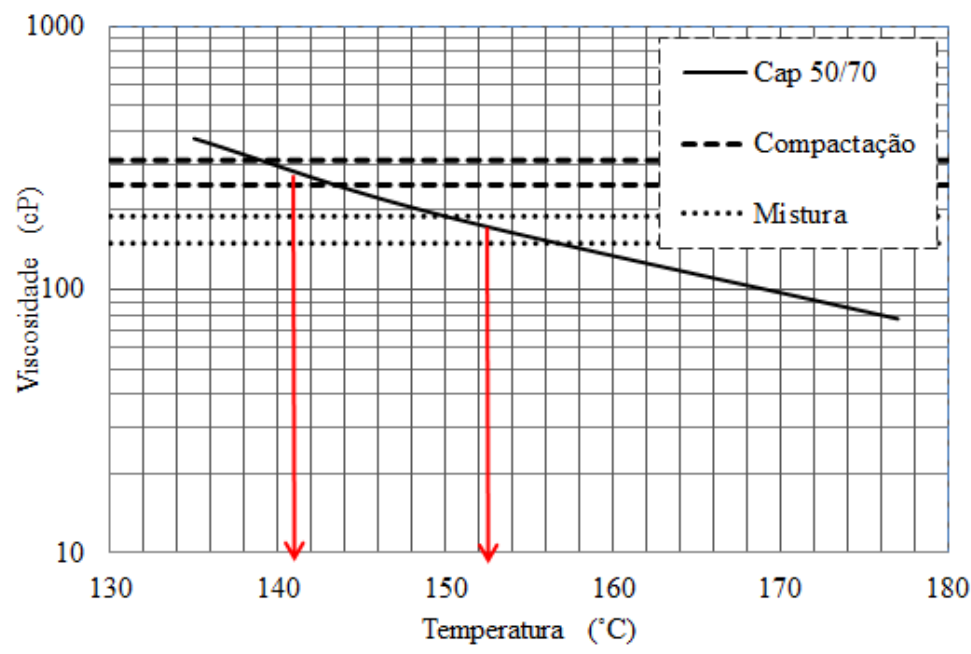

Figura 3: Curva viscosidade $\mathrm{x}$ temperatura do ligante novo utilizado nas misturas 


\subsection{Dosagem e definição do teor de projeto}

Optou-se pela verificação do volume de vazios ( Vv), correspondente a 4\%, como parâmetro para encontrar o teor de ligante asfáltico necessário para a mistura. Partindo deste princípio, foram desenvolvidos os cálculos para as misturas M100 e M50.

Para a M100 foram moldados conjuntos de 5 corpos de prova para diferentes teores de CAP. Partindo do teor médio de ligante de 5,35\%, obtido através do ensaio de extração de uma amostra fresada, considerouse uma adição de 2,5\% a 4,0\% de ligante novo. Utilizaram-se teores de CAP semelhantes aos usuais em misturas novas, não sendo considerada a utilização de agentes rejuvenescedores para recuperar o ligante envelhecido.

Para a M50 optou-se por começar a dosagem com um teor de ligante maior, devido à presença de agregados novos. Definidas as temperaturas de mistura e compactação, foram moldados 3 corpos de prova para cada teor de ligante novo, adicionados à mistura, variando de 2,5\% a 4,5\%.

A Tabela 1 indica os teores de CAP utilizados para desenvolvimento das duas misturas e o teor total considerando o ligante presente no material reciclado.

Tabela 1: Porcentagens de acréscimo de ligante novo nas misturas

\begin{tabular}{c|c|c|c}
\hline \multirow{4}{*}{ Mistura } & $\begin{array}{c}\text { CAP envelhe- } \\
\text { cido presente } \\
\text { no fresado }(\%)\end{array}$ & $\begin{array}{c}\text { CAP novo } \\
\text { adicionado à } \\
\text { mistura (\%) }\end{array}$ & $\begin{array}{c}\text { CAP total } \\
\text { da mistura } \\
(\%)\end{array}$ \\
\hline \multirow{4}{*}{ M100 } & 5,35 & 2,50 & 7,85 \\
\cline { 2 - 4 } & 5,35 & 3,00 & 8,35 \\
\cline { 2 - 4 } & 5,35 & 3,50 & 8,85 \\
\hline \multirow{4}{*}{ M50 } & 5,35 & 4,00 & 9,35 \\
\cline { 2 - 4 } & 2,67 & 2,50 & 5,15 \\
\cline { 2 - 4 } & 2,67 & 3,00 & 5,67 \\
\cline { 2 - 4 } & 2,67 & 3,50 & 6,17 \\
\cline { 2 - 4 } & 2,67 & 4,00 & 6,67 \\
\hline
\end{tabular}

\subsection{Moldagem e rompimento dos corpos de prova}

Com a definição das misturas e da variação do teor de ligante de cada dosagem foram moldados os corposde-prova (CP). Os corpos de prova foram moldados da seguinte maneira:

- M100: Moldagem de 12 CP's, sendo 3 para cada dosagem. As dosagens tiveram adição de ligante novo variando de $2,5 \%$ a $4,0 \%$;

- M50: Moldagem de 15 CP's, sendo 3 para cada dosagem. As dosagens tiveram adição de ligante novo variando de $2,5 \%$ a $4,5 \%$.

As misturas foram compactadas a uma temperatura em torno de $142^{\circ} \mathrm{C}$, respeitando os limites encontrados no ensaio de viscosidade, com auxílio de um compactador Marshall. Foram aplicados 75 golpes como energia de compactação, definidos pela norma DNER-ME 043 (1995) [20]. A desmoldagem dos corpos-deprova ocorreu logo após o resfriamento dos mesmos, utilizando um macaco hidráulico do tipo garrafa.

Após a desmoldagem, os corpos de prova foram mantidos em repouso por 24 horas à temperatura ambiente. Os valores de Gmb (massa específica aparente da mistura) foram encontrados com base na média de 3 corpos-de-prova para cada teor de ligante novo adicionado às dosagens das misturas M100 e M50. Os resultados de Gmm (massa específica máxima medida) são relativos à média de duas amostras de cada uma das dosagens desenvolvidas para as misturas, obtidos através do procedimento de Rice, o qual obedece a NBR 15619 (2012) [12] para misturas asfálticas.

Os corpos-de-prova utilizados para encontrar o volume de vazios foram ensaiados para determinação da estabilidade e fluência, novas amostras foram moldadas com teor de ligante que gerasse amostras com volume de vazios de $4 \%$ para determinação da resistência à tração.

Para determinação da estabilidade e fluência, a carga foi aplicada aos corpos-de-prova a uma temperatura de $60^{\circ} \mathrm{C}$ com taxa de velocidade de aplicação de carregamento de $5 \mathrm{~cm} /$ minuto. Foram obtidos os valores 
da estabilidade, lida em N (Newton), e da deformação (fluência), em mm (milímetros).

O ensaio para determinação da resistência à tração foi executado conforme a norma do Departamento Nacional de Infraestrutura de Transportes DNIT - ME 136/2010 [21]. O ensaio foi conduzido com aplicação de carga com taxa de velocidade de $0,8 \mathrm{~mm} / \mathrm{s}$ e rompidos à temperatura de $25^{\circ} \mathrm{C}$. Deste ensaio obteve-se a carga de ruptura F, expressa em N (Newton). Com esta carga, a resistência à tração foi determinada em função da área da seção transversal do corpo de prova, sendo apresentada em MPa.

\section{RESULTADOS}

\subsection{Ensaios de caracterização mecânica e volumétrica}

Para a M100, as dosagens obtiveram limite inferior de 2,5\% e limite superior de 4,0\%, variando $0,5 \%$ o teor de ligante em cada dosagem. Dessa forma, foram produzidas 4 dosagens para essa mistura e moldados 12 corpos de prova, sendo 3 para cada teor. A Tabela 2 indica os parâmetros volumétricos encontrados para o grupo de corpos de prova da M100.

Analisando a M50, as dosagens obtiveram limite inferior de 2,5\% e limite superior de 4,5\%, variando $0,5 \%$ o teor de ligante em cada dosagem. Foram produzidas 5 diferentes dosagens para a mistura e moldados 15 corpos de prova, sendo 3 para cada teor. A Tabela 2 apresenta os resultados obtidos para os parâmetros volumétricos dessa mistura. Os dados de Vv e RBV são mostrados nas Figuras 4 e 5, respectivamente, e os limites especificados pelo DNIT (2006) [17] para a faixa C.

Tabela 2: Média dos parâmetros das misturas e os limites do DNIT (2006)

\begin{tabular}{|c|c|c|c|c|c|c|c|c|c|}
\hline \multirow{2}{*}{ Parâmetros } & \multicolumn{4}{|c|}{$\operatorname{M100}(\%)$} & \multicolumn{5}{|c|}{$\operatorname{M50}(\%)$} \\
\hline & 2,50 & 3,00 & 3,50 & 4,00 & 2,50 & 3,00 & 3,50 & 4,00 & 4,50 \\
\hline $\mathbf{G a}\left(\mathrm{g} / \mathrm{cm}^{3}\right)$ & 1,10 & 1,10 & 1,10 & 1,10 & 1,10 & 1,10 & 1,10 & 1,10 & 1,10 \\
\hline $\mathbf{G m b}\left(\mathbf{g} / \mathbf{c m}^{3}\right)$ & 2,15 & 2,16 & 2,17 & 2,20 & 2,21 & 2,24 & 2,26 & 2,28 & 2,33 \\
\hline $\operatorname{Gmm}\left(\mathrm{g} / \mathrm{cm}^{3}\right)$ & 2,27 & 2,28 & 2,28 & 2,29 & 2,35 & 2,36 & 2,36 & 2,37 & 2,37 \\
\hline Teor de projeto (\%) & 7,85 & 8,35 & 8,85 & 9,35 & 7,85 & 8,35 & 8,85 & 9,35 & 9,85 \\
\hline $\begin{array}{l}\text { Teor de CAP enve- } \\
\text { lhecido }(\%)\end{array}$ & 5,35 & 5,35 & 5,35 & 5,35 & 5,35 & 5,35 & 5,35 & 5,35 & 5,35 \\
\hline $\mathrm{Vv}(\%)$ & 5,28 & 4,95 & 4,86 & 3,72 & 5,82 & 4,67 & 4,13 & 3,46 & 1,80 \\
\hline $\operatorname{VCB}(\%)$ & 15,34 & 16,41 & 17,45 & 18,70 & 17,37 & 18,75 & 20,02 & 21,35 & 22,92 \\
\hline VAM (\%) & 20,63 & 21,37 & 22,31 & 22,42 & 23,20 & 23,42 & 24,16 & 24,81 & 24,73 \\
\hline $\operatorname{RBV}(\%)$ & 74,39 & 76,81 & 78,21 & 83,41 & 74,90 & 80,04 & 82,89 & 86,05 & 92,70 \\
\hline
\end{tabular}

Ga: Massa específica do ligante; Gmb: Massa específica aparente da mistura; Gmm: Massa específica máxima medida; Vv: Volume de vazios; VCB: Vazios com betume; VAM: Vazios do agregado mineral; RBV: Relação betume vazios.

Com base nos parâmetros de $\mathrm{Vv}$ foi possível determinar o teor correspondente ao $\mathrm{Vv}$ de $4,0 \%$, para ambas as misturas, sendo este volume especificado pelo DNIT (2006) [15]. Para a M100, observa-se que o teor ótimo de ligante correspondente ao Vv de 4,0\% será de 3,87\%. Para M50 o teor de projeto, correspondente ao Vv de 4,0\%, é igual a 3,6\%. 


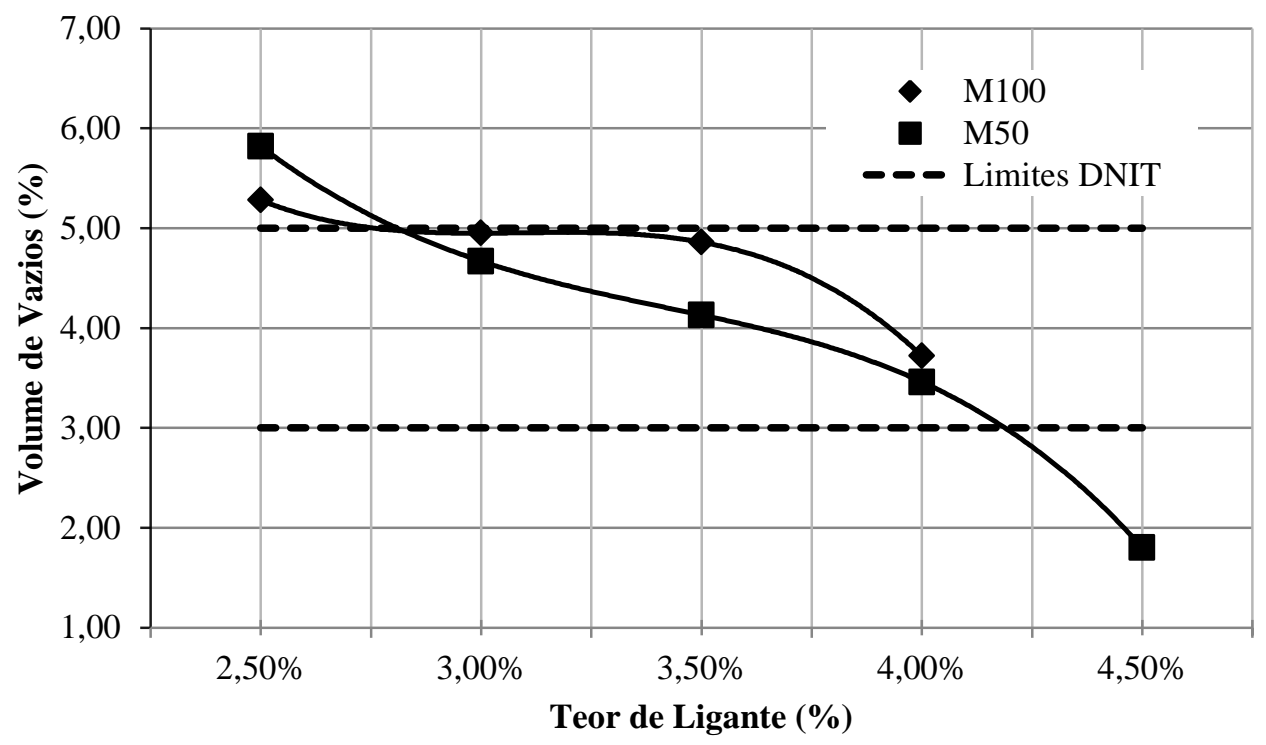

Figura 4: Volume de vazios versus teor de ligante das misturas analisadas

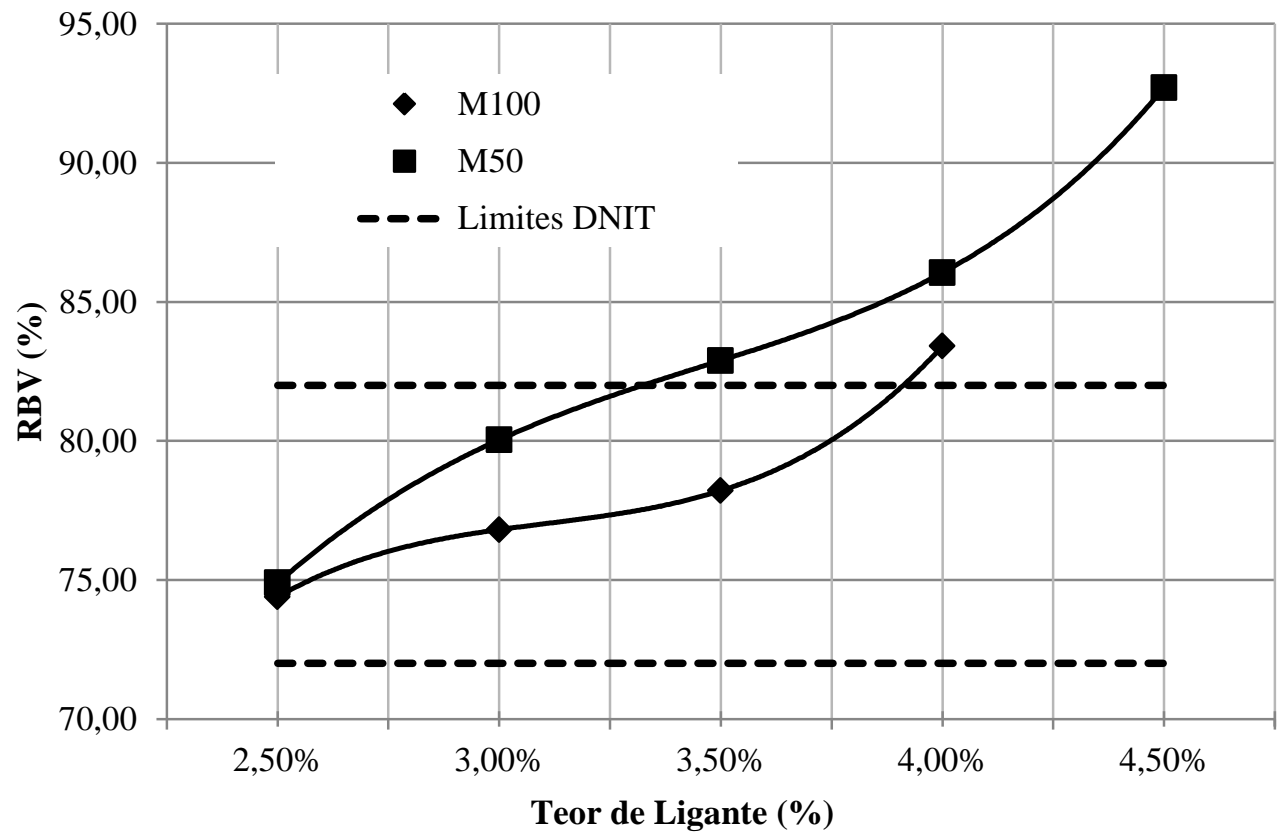

Figura 5: RBV versus teor de ligante das diferentes misturas analisadas

\subsection{Caracterização mecânica das amostras no teor de ligante}

A Figura 6 apresenta a média da resistência à tração obtida para os corpos de prova das misturas M100 e M50, rompidos 24 horas após a moldagem. É possível ainda verificar a resistência mínima preconizada por norma, em comparação com os resultados encontrados. 


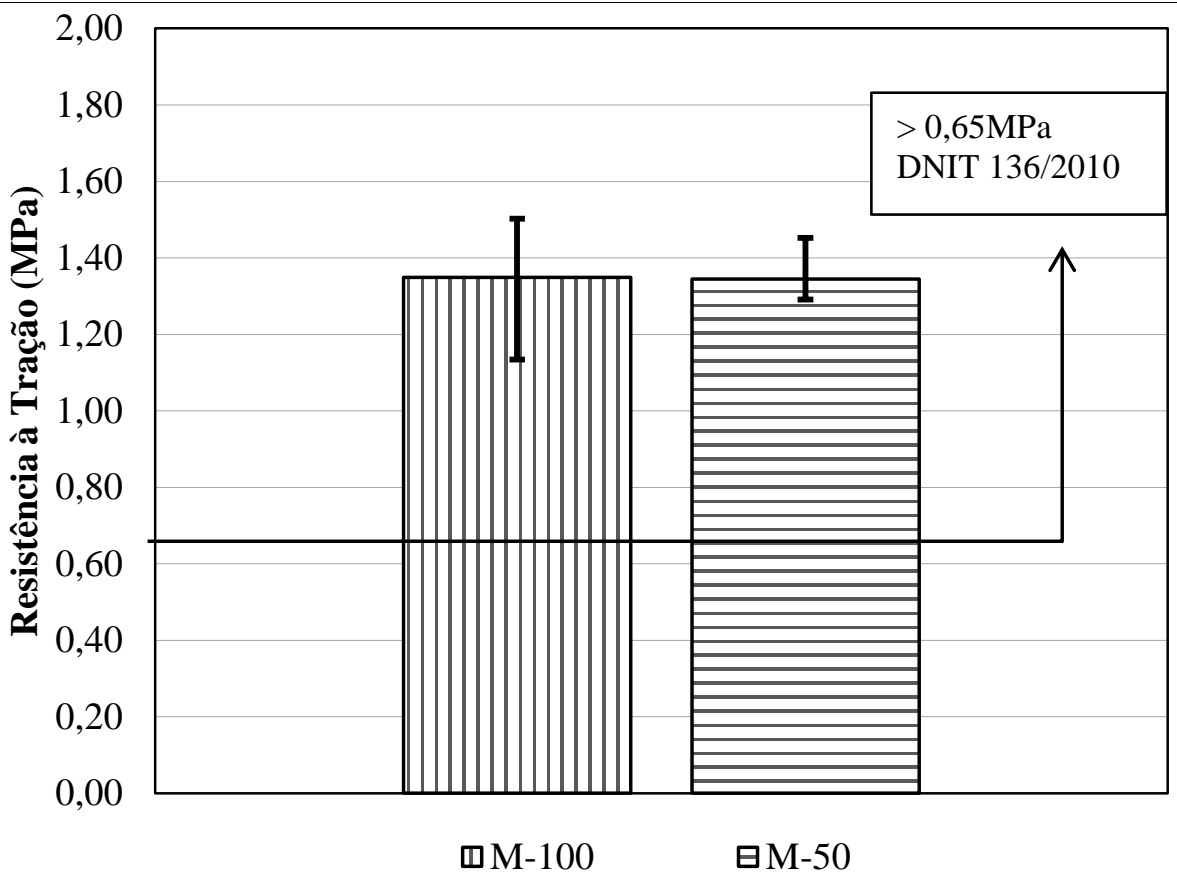

Figura 6: Média da resistência à tração das misturas M100 e M50

Observa-se, com base na Figura 6, que os valores encontrados foram satisfatórios para ambos os tipos de misturas avaliadas no estudo. Ainda, é possível ressaltar que as resistências encontradas estão coerentes com os valores típicos verificados em corpos de provas de recém-moldados de misturas asfálticas. Essas misturas apresentam valores médios de resistência à tração situados entre 0,5 $\mathrm{MPa}$ e 2,0 $\mathrm{MPa}$ [23].

A partir da incorporação de material fresado a taxas superiores a $25 \%$, encontram-se valores menores de resistência à tração [24,25]. Isso se deve ao fato de materiais fresados acarretarem à mistura um volume de vazios maior e, consequentemente, queda na sua resistência. No entanto, não houve queda na resistência à tração no presente estudo, uma vez que a média das resistências à tração, obtidas para a M100, foi igual para a M50, apresentando, entretanto, uma maior variação nas resistências entre as amostras ensaiadas, conforme representado pelas barras de erros com os valores máximos e mínimos obtidos em cada conjunto de ensaios.

\section{DISCUSSÃO}

Avaliando as características das misturas estudadas ao longo da pesquisa fica claro que a incorporação de material fresado em novas misturas de revestimentos asfálticos é uma técnica que atende aos requisitos mínimos para o bom desempenho de uma pista de rolamento. Isto se justifica desde que sejam realizadas as análises necessárias para definição das proporções de materiais reciclados e novos a serem introduzidos na composição da nova mistura. Entretanto, torna-se indispensável realizar ensaios com carregamento dinâmico como, por exemplo, ensaios de módulo de resiliência e fadiga para verificar se o comportamento nestes ensaios continuará viabilizando o uso dessas misturas.

Portanto, para as duas misturas propostas no estudo, houveram diferenças significativas nas propriedades volumétricas da mistura com $100 \%$ de material reciclado (M100) e da mistura com adição de 50\% de material virgem (M50), e, desta forma, qualquer pequena variação nas características do material fresado deve ser levada em conta e, portanto, deve ser feita uma classificação do material fresado para que seja o mais uniforme possível ao longo do seu uso.

Verificou-se, ainda, que, em relação ao Vv, a M100, composta de 100\% de material fresado, obteve três teores estudados dentro dos limites especificados pelo DNIT (2006) [15], o qual permite volume de vazios entre 3\% e 5\%. Para a M50, também três dosagens apresentaram resultados que atenderam este critério.

Para definição do teor de projeto, considerou-se, neste estudo, apenas o volume de vazios de $4 \%$ requerido pelo DNIT (2006) [15]. Com isso, obteve-se, para a M100, um teor de projeto de 3,87\% e para a M50, de 3,6\%. Nota-se que o teor de asfalto necessário para a M100 alcançar um Vv de 4\% é um pouco maior do que o necessário para a M50. Isto se justifica devido a M50 ter passado por uma correção granulométri- 
ca, no momento de sua composição com adição de agregados virgens, o que proporcionou uma maior quantidade de finos na mistura. O mesmo não ocorreu para a M100, já que o material fino presente no fresado estava na forma de grumos com granulometria maior em, praticamente, todas as amostras.

$\mathrm{Na}$ avaliação da resistência à tração por compressão diametral, as misturas M100 e M50 foram ensaiadas com o teor de projeto. Ambas as misturas obtiveram valores de resistência superiores a 0,65 $\mathrm{MPa}$, indicado por norma, com valor aproximado de 1,35 MPa para as duas misturas. Através da literatura, observa-se uma tendência de aumento da RT com o aumento do teor de fresado [26], fato este que não foi comprovado, visto que os valores ficaram muito próximos para 50\% e 100\% de fresado. Oliveira (2013) [27], encontrou valor de RT da ordem de 2,2 MPa para mistura asfáltica reciclada morna com 50\% de fresado, estando bem acima do valor encontrado nesta pesquisa com a dosagem a quente. No entanto, Lima (2003) [26] encontrou valor de RT de 1,60 MPa para a mesma porcentagem de fresado adicionada na mistura reciclada desta pesquisa.

\section{CONCLUSÕES}

Com base no exposto, verifica-se que as misturas asfálticas com material reciclado apresentam desempenho similar e, em alguns casos, superiores às misturas convencionais. Ainda, é possível destacar que o estudo proporcionou maior conhecimento a respeito da aplicação de material fresado em misturas asfálticas para camadas de revestimento e, ainda, que os valores encontrados foram satisfatórios para os projetos de misturas desenvolvidos nesta pesquisa. Com isso, a pesquisa tende a auxiliar projetistas e órgãos executores no momento da escolha de materiais adequados para os revestimentos, visando, ainda, a questão ambiental, já que a utilização de material fresado reduz a extração de fontes de recursos naturais. Destaca-se ainda, que com o reaproveitamento do material fresado haverá menor consumo de agregados virgens, e não será necessário criar áreas para o deposito do material fresado.

\section{BIBLIOGRAFIA}

[1] BONFIM, V. Fresagem de Pavimentos Asfálticos. 3 ed., São Paulo, Exceção, 2007.

[2] VASCONCELOS, K. L., SOARES, J. B., Influência do percentual de fresado e do envelhecimento de curto prazo na dosagem de misturas asfálticas recicladas a quente. Universidade Federal do Ceará, XVIII ANPET - Congresso de Pesquisa e Ensino em Transportes. Anais. Florianópolis/SC, 2004.

[3] SUZUKI, C. Y., PEREIRA, A. C. O., AZEVEDO, A. M., et al., "Avaliação estrutural de trecho experimental urbano de pavimento asfáltico reciclado a frio", In: $35^{\circ}$ Reunião Anual de Pavimentação, Rio de Janeiro, 2004.

[4] ROSA, P., LORENZO, C., PACHECO, A. "Material fresado - de problema à solução econômica em obras de pavimentação", In: 38 Reunião Anual de Pavimentação, Manaus, 2007.

[5] FONSECA, P., GUIMARÃES, C., GOMES, V., et al., Estudo de Material Fresado para Incorporação em Misturas Betuminosas a Quente com Altas Taxas de Reciclagem. Universidade do Minho, C-TAC - Centro do Território Ambiente e Construção, Campus de Azurém, Guimarães, Portugal, 2013.

[6] DANTAS, T. N. C., BARROS NETO, E. L., GOMES FILHO, F. F., et al., "Reciclagem de material asfáltico fresado com a utilização de solventes e microemulsões", In: $4^{\circ}$ Congresso Brasileiro de Pesquisa e Desenvolvimento em Petróleo e Gás - PDPETRO, Campinas- SP, 2007.

[7] DAU, F. N. F. Uma avaliação técnico/econômica da reciclagem de revestimentos asfálticos a frio em usina em área urbana. Dissertação de M.Sc., Universidade Federal do Rio Grande do Sul, Porto Alegre, Brasil, 2001.

[8] CONSELHO NACIONAL DO MEIO AMBIENTE. Resolução CONAMA nº 307, de 05 de julho de 2002. Estabelece diretrizes, critérios e procedimentos para a gestão dos resíduos da construção civil. Diário Oficial da República Federativa do Brasil, 2002.

[9] MOREIRA, J. P. V., PEREIRA, P., CORREIA, A. G., "Reutilização de material fresado em camadas estruturais de pavimento", In: IV Congresso Rodoviário Português - Centro de Congressos do Estoril, 2003.

[10] MOHAJERI, M., MOLENAAR, A. A. A., VAN DE VEM, M. F. C., "Bleding Simulation of RA and Virgin Binders in Hot Recycled Mixtures", In: $8^{\text {th }}$ RILEM International Symposium on Testing and Characterization of Sustainable and Innovative Bituminous Materials, v. 11, 2015. 
[11] BRESSI, S., CAVALLI, M. C., PARTL, M. N., et al., "Particle clustering phenomena in hot asphalt mixtures with high content of reclaimed asphalt pavements", Journal Construction and Building Materials, v. $100,2015$.

[12] SEGUNDO, I. G. R., CASTELO BRANCO, V. T. F., VASCONCELLOS, K. L., et al., "Misturas asfálticas recicladas a quente com incorporação de elevado percentual de fresado como alternativa para camada de módulo elevado", Revista Transportes, v. 24, n 4, pp. 85-94, 2016.

[13] DANIEL, J. S., LACHANCE, A., "Mechanistic and volumetric properties of asphalt mixtures with RAP", Journal of the Transportation Research Board, v. 1929, 2005.

[14] MENCHING, D. J., DANIEL, J. S., BENNERT, T., et al., "Low temperature properties of plant produced RAP mixtures in the Northeast", Journal of Road Materials and Pavement Design, v. 15, 2014. DOI: 10.1080/14680629.2014.926617.

[15] DEPARTAMENTO NACIONAL DE INFRAESTRUTURA DE TRANSPORTES, Manual de Pavimentação, Rio de Janeiro, 2006.

[16] DEPARTAMENTO NACIONAL DE ESTRADAS DE RODAGEM DNER-ME 053/1994, Misturas betuminosas percentagem de betume - Método de Ensaio, Rio de Janeiro, 1994.

[17] DEPARTAMENTO NACIONAL DE INFRAESTRUTURA DE TRANSPORTES, DNIT-ES 031/2006: Pavimentos flexíveis - Concreto asfáltico - Especificação de serviço, Rio de Janeiro, 2006.

[18] DEPARTAMENTO NACIONAL DE ESTRADAS DE RODAGEM, DNER-ME 083/1998: Agregados - análise granulométrica - Método de ensaio, Rio de Janeiro, 1998.

[19] ASSOCIAÇÃO BRASILEIRA DE NORMAS TÉCNICAS, NBR-15184 - Materiais betuminosos - Determinação da viscosidade em temperaturas elevadas usando um viscosímetro rotacional. Rio de Janeiro, 2004.

[20] DEPARTAMENTO NACIONAL DE ESTRADAS DE RODAGEM, DNER-ME 043: Misturas betuminosas a quente - Ensaio Marshall - Método de Ensaio, Rio de Janeiro 1995.

[21] DEPARTAMENTO NACIONAL DE INFRAESTRUTURA DE TRANSPORTES, DNIT-ME-136: Pavimentação asfáltica - Misturas asfálticas - Determinação da resistência à tração por compressão diametral. Método de ensaio, Rio de Janeiro, 2010.

[22] ASSOCIAÇÃO BRASILEIRA DE NORMAS TÉCNICAS, NBR-15619 - Misturas asfálticas - Determinação da massa específica máxima medida em amostras não compactadas. Rio de Janeiro, 2012.

[23] BERNUCCI, L., MOTTA, L. G., CERATTI, J. A. P., et al., Pavimentação Asfáltica: Formação Básica para Engenheiros, 1 ed., Rio de Janeiro, ABEDA, 2008.

[24] NASCIMENTO, M. V., Estudo do comportamento mecânico de misturas asfálticas recicladas, Dissertação de M.Sc., Programa de Pós-Graduação de Engenharia Civil e Ambiental da Universidade Federal de Campina Grande, Campina Grande, Brasil, 2011.

[25] ALMEIDA JUNIOR, P. O. B. Comportamento mecânico de concretos asfálticos com diferentes granulometrias, ligantes e métodos de dosagem, Dissertação de M.Sc., Programa de Pós-Graduação em Engenharia Civil da Universidade Federal de Santa Maria, 2016.

[26] LIMA, A. T. Caracterização mecânica de misturas asfálticas recicladas a quente, Dissertação de M.Sc., Universidade Federal do Ceará, Fortaleza, 2003.

[27] OLIVEIRA, J. A. Avaliação do desempenho de misturas asfálticas recicladas mornas em laboratório e em campo, Dissertação de M.Sc., Engenharia de Transportes, Universidade Federal do Ceará, Fortaleza, 2013. 